\title{
J. Bravo Carbonel e José de Macedo: duas leituras coloniais dos trópicos
}

\author{
Cátia Miriam Costa ${ }^{1}$
}

\begin{abstract}
RESUMO: Tendo como ponto de partida duas obras de Bravo Carbonel e José de Macedo, respetivamente, um espanhol e um português, este ensaio basear-se-á na comparação de conteúdos e estéticas associadas à literatura colonial produzida por ambos. Assim, serão analisadas as várias relações dicotómicas a que os autores se referem, logo temáticas partilhadas: metrópole/colónia; colonizador/colonizado; utópico/real; indígena/civilizado.
\end{abstract}

ABSTRACT: On the basis of two works of Bravo Carbonel and José de Macedo, respectively, one Spanish and one Portuguese, this essay will be based on comparison of content and aesthetic associated with the colonial literature produced by both. This will examine the various dichotomous relationship that the authors refer, once shared theme: metropolis / colony, colonizer / colonized; utopian / real; indigenous / civilized.

PALAVRAS-CHAVE: Colonização; Utopia; Exótico

KEYWORDS: Colonization; Utopia; Exotic

Partimos de duas obras, escritas por J. Bravo Carbonel e José de Macedo, denominadas Fernando Poo y el Muni: sus mistérios y riquezas. Su Colonización e Autonomia de Angola: estudo de administração colonial, respetivamente, com as suas primeiras edições em 1917 e 1910. Escritos com objetivos muito precisos, que adiante exploraremos, o mais importante dos quais "a propaganda dos territórios colonizados", não deixam de poder ser considerados, na forma e na estética que preconizam, literatura colonial. Aliás, é perfeitamente identificável uma relação entre forma e conteúdo, aprofundada ao máximo por ambos autores.

1 Doutoranda na Universidade de Évora. Projeto: Utopia colonial. Contato: catia_miriam1@hotmail.com 
Vejamos agora quem são os autores, outro elemento indispensável para procedermos a uma análise comparativa. J. Bravo Carbonel é um funcionário da administração colonial que vive três anos nos territórios da então Guiné Equatorial, enquanto responsável pela área veterinária da colónia, estando, portanto, a cumprir uma comissão administrativa (BRAVO CARBONEL, 1917, p. 8)². José de Macedo é jornalista e vai dirigir o jornal A Defeza de Angola $^{3}$, depois de perseguido na metrópole, devido às ideias republicanas em tempos da monarquia, permanecendo em Angola durante cerca de quatro anos, interrompida a sua estada por motivos de doença de sua esposa (MACEDO, 1910, p. 217). O primeiro está ao serviço do Estado, no prosseguimento da sua carreira, o outro opõe-se ao Estado, um tem formação veterinária e o outro formação económica, um crê que vai servir o Estado e o outro acredita estar a servir a sociedade civil.

Contudo, as conjunturas internas e externas dos seus países aproximam-nos em alguns aspetos, tornando-os faces divergentes de uma mesma época. Ambos enraízam o seu pensamento no positivismo que caracteriza os movimentos intelectuais deste período, transpondo esse vínculo para a sua escrita, senão vejamos: ilustram as suas opiniões profusamente com dados objetivos (estatísticos, reais e projetados), servem-se do elemento comparativo entre países e situações para melhor marcar a sua posição e, neste caso, recorrendo sempre a situações reais de que têm conhecimento. Defendem, igualmente, a necessidade de tirar a população autóctone do seu estado de "atraso", mas fazem-no sugerindo métodos diferentes e, igualmente, focando-se em objetivos diversos.

As obras a que nos reportamos são, de modo idêntico, dirigidas ao leitor metropolitano, em primeiro plano, e os colonos residentes nos espaços coloniais são tratados num plano secundário. Estes públicos

\footnotetext{
2 O prefaciador do livro, Tomás Maestre, acrescenta que J. Bravo Carbonel foi Oficial Facultativo do Exército e veterinário militar (Maestre 1917, p. IX-XVI e XIV-XV) 3 José de Macedo terá assumido a direção do jornal em Maio de 1906, segundo a sua própria indicação na primeira página, do n. ${ }^{\circ}$ 262, de dia 21 de Fevereiro, por ocasião do quarto aniversário do jornal (Macedo, 1906, p. 1).
} 
têm, igualmente, aspetos em comum, encontrando-se acossados pela perda de poder externo dos seus países, traduzida na privação dos seus antigos territórios coloniais e na contrariedade dos seus argumentos históricos relativamente à posse de vastos territórios, aparentemente sem dono. São leitores mergulhados na incerteza das convulsões internas e no questionamento das suas reais capacidades. Depois de tão grandes feitos acometidos, veem-se maltratados pelas opiniões públicas e governos estrangeiros. Humilhados na sua matriz cultural, são, portanto, leitores em busca de um caminho que os liberte desse desprestígio paulatino que mina a sua própria confiança nos empreendimentos do presente e do futuro. Os sete anos (1910-1917) que separam estas obras não alteram este estado de coisas, apesar de 1910 ter sido um ano de revolução em Portugal, com a Implantação da República. O ciclo das nações ibéricas não alterou o seu curso nesse período de tempo, nem a história ou o presente tinham sofrido reinterpretações; a conjuntura externa e a instabilidade interna mantinham-se e ameaçavam ficar durante o que parecia uma conjunção infindável.

\section{Dois percursos ibéricos em terras africanas}

Os dois autores explicam-nos o percurso dos seus países em cada um dos territórios colonizados. A Guiné Equatorial, enquanto espaço colonial, é construída a partir de negociações diplomáticas, primeiro com Portugal e seguidamente com as potências coloniais europeias que pretendem fixar fronteiras, fazendo Espanha recuar em termos de território histórica e previamente consignado em tratado com Portugal. Agora prevalecia a ocupação efetiva e a verdade é que Espanha não tinha ocupado os vastos territórios africanos de que até então dispunha (BRAVO CARBONEL, p. 8-12). Angola por seu lado, é descrita como tendo uma ocupação antiga, fixada em pontos do litoral, cujo comércio florescia em redor de relações esporádicas com o interior do território. A recente corrida à África destruíra as ambições 
portuguesas de ligar o Atlântico ao Índico, mas consignara-lhe um território vasto, com parte das populações ambientadas à presença portuguesa e outra parte alvo de campanhas duras de submissão. Por volta de 1910, Angola estava pacificada e quase ocupada, salvo revoltas pontuais, mas de violência considerável, em que os povos do sertão tentavam repelir a apropriação das suas terras (MACEDO, p. 125-134). Dado o percurso já longo, pelo menos, em termos formais dos poderes ibéricos nos territórios, os autores introduzem-nos nesses caminhos da história e dos diplomas administrativos. Se as metrópoles pareciam estar próximas nos seus desafios de presente e futuro, estes territórios coloniais eram descritos como formas bastante dissemelhantes.

A independência das colónias da América e a perda de territórios associados a outras possessões lançam estes dois países numa derradeira tentativa de afirmação em África, sentindo-se ultrapassados por todos aqueles países europeus que não deram novas nações ao mundo, não descobriram nem trilharam caminhos indómitos, não "civilizaram" o outro nem fizeram de desertos verdadeiros Estados. É nessa revolta e na vontade de afirmação interna e externa da posição destes países que se mobiliza o público, esse leitor que ajudará a mudar o rumo das coisas, essa assistência que lê e re-elabora o texto, que pesa argumentos, compara experiências e, no final, formará uma opinião, primeiro passo para uma cidadania ativa que ambos os autores procuram se bem que com finalidades diferentes. Essa profunda ligação entre passado e presente, entre América e África, entre perda de colónias e construção de um novo tecido colonizador e colonial, espelhase nos exemplos comuns que encontramos em ambas as obras, em que, de fato, vemos como referência tanto de um lado como do outro a situação colonial vizinha. Se J. Bravo Carbonel compara mais do que uma vez a situação de São Tomé à da Ilha de Fernando Pó e, no prefácio à sua obra, Tomás Maestre compara a posição colonial de Portugal e Espanha à época (BRAVO CARBONEL, p. 129-130; MAESTRE, 1917, p. $\mathrm{X})$; José de Macedo exemplifica com Cuba, o previsivel futuro de Angola, caso não haja uma maior descentralização e progressiva autonomia 
(MACEDO, p. 118-120). Curiosamente ou não, ambos os autores se referem ao degredo político dos dissidentes cubanos que foram condenados a ir para Fernando Pó, exatamente na Guiné Equatorial, mas por razões diferentes, um assim justificando a má fama da Guiné entre a população metropolitana; o outro explicando que a solução nunca pode ser afastar os dissidentes autonomistas, mas antes ouvi-los e com eles trabalhar para um futuro comum (BRAVO CARBONEL, p. 121; MACEDO, p. 146).

\section{Duas jornadas, dois discursos sobre África}

O modo como estes intelectuais interpretam os trópicos é, em parte, tributário dos seus percursos nestes espaços tropicais, tão diversos dos seus locais de origem. Ambos acreditando prestar um serviço de alto patriotismo ao seu país, trilham caminhos para estes territórios no sentido do inexorável progresso, única maneira de os povos proverem às suas necessidades. Um progresso, como sabemos, enraizado na experiência europeia, à boa maneira positivista. Estas condicionantes são determinantes na construção dos discursos coloniais que estamos a analisar. J. Bravo Carbonel segue para a Guiné Equatorial como servidor do Estado, José de Macedo como opositor ao Estado, o que resulta em construções discursivas logo à partida diversas. O primeiro é consequência da vivência temporária de um europeu (espanhol) em África que vê o mundo tropical a partir da Península Ibérica, apesar de ter lá estado fisicamente; o segundo é resultante da convivência de um europeu (português) em África que reconheceu nos intelectuais angolanos mérito (colonos e autóctones civilizados) e que vê os trópicos a partir de Angola 4 .

Deste modo, a disparidade de ambos os discursos começa logo no ponto de partida e vai-se afirmando, paulatinamente, no decorrer dos

\footnotetext{
4 José de Macedo refere mesmo ter pensado nunca voltar à metrópole para viver, mas como regressou decide manter os seus ideais de propaganda pela melhoria da situação angolana. MACEDO, p. 217. Nota: A palavra "propaganda" é aqui utilizada no sentido que lhe dá o autor, no início do século XX.
} 
textos. O discurso elaborado por J. Bravo Carbonel caracteriza-se pelo distanciamento do "outro", pelo recurso às imagens belas e exóticas, envolvendo o leitor pelos sentidos, fruto de uma descrição em que as cores, as texturas e até os cheiros abundam 5 . Mesmo referindo-se a situações perfeitamente casuais e correntes, como o pôr-do-sol, há o recurso a este artificio em que todas as palavras adquirem um peso simbólico que aponta para o exotismo e para a diferença face à realidade conhecida pelo leitor.

Los crepúsculos, de incomparable belleza, son muy fugaces. El sol, que luce con todo su fuego, se para un instante en el horizonte, y al declinar tienen primorosos cambiantes y el paisaje, que era de luz de fuego, de oro, se tornas en rojo púrpura, grana, ámbar, gris, violeta. Se funden, se disuelven con rapidez unas tonalidades en otras, y las que antes eran de lujuria, son luego de mansa poesía, de melancolía después. (...) La noche, dueña del misterio ha llegado. (BRAVO CARBONEL, p. 31)

O discurso criado por José de Macedo ganha a forma de exposição, chegando a atingir os contornos do manifesto político, pelo uso de imperativos e pela predominância de descrições políticas, numa linguagem objetiva, recheada de exemplos reais, quase com a clareza de uma reportagem posta ao serviço da defesa de um ideal, procurando a aproximação ao "outro" que, também ele, precisa ser cativado para este fim. Como exemplo, transcrevemos a conclusão de um raciocínio que começa com a apresentação dos direitos em falta na, então, colónia angolana (direito à educação, direito à saúde, direito à comunicação e à circulação e direito ao trabalho).

Em Lisboa não se atende às necessidades da colónia, que é um explendido specimen geográfico, situada numa parte de Africa que lhe marca, para assim dizer, um logar de passagem, para o Atlantico, de todos os produtos da Africa do sul e do centro, em direcção aos mercados da Europa. E diga-se, francamente, que a culpa não é, apenas, dos governos. (MACEDO, p. 8)

5 A descrição é, ainda, enriquecida com fotografias da autoria do autor que assim ilustra o texto. 
Ambos se dirigem diretamente ao leitor, quando o consideram necessário, no sentido de com ele estabelecerem uma espécie de diálogo. Em José de Macedo este assume um caráter coloquial, enquanto que em J. Bravo Carbonel o leitor é mais passivo, sendo este abordado quase no final do livro e com o objetivo muito preciso de acompanhar os seus cálculos e razões para considerar a Guiné Equatorial como um território proficuo e com vastas possibilidades para o colonizador (BRAVO CARBONEL, p. 281). José de Macedo, no decurso da sua obra explica as suas motivações, partilha aspetos pessoais e profissionais da sua vida e não hesita em invocá-los perante o leitor que participa de toda a descrição factual que envolve o seu discurso (MACEDO, p. 163-165). Assim sendo, chega a criar uma relação de cumplicidade com o leitor que vai conhecendo até os pormenores da sua experiência de modo a estar alerta para os perigos enunciados pelo autor.

(...) uma noite fui assaltado por uns 6 ou 7 , quando em companhia de Antonio Perez jantava socegadamente no hotel Areias, em Loanda. (...) Qual era o dever da polícia e do administrador do concelho em face disto?

Pois, não senhor; o administrador mandou prender-me e benevolamente informava em confidencial o governador, seu padrasto, de que eu era um elemento perigoso e muito conhecido pela polícia de Lisboa e Porto.

(...) Quem sabe se um dia com a república se repetirá o mesmo acontecimento? (MACEDO, p. 165, itálico do autor)

Aliás o recurso a este estilo de escrita é comum tanto nesta época como na que corresponde à geração de escritores e intelectuais precedente, sendo a coloquialidade e o diálogo com o leitor recorrentes, numa tentativa de aproximação ao mesmo, sobretudo quando a obra pretende ter um caráter de divulgação ou uma função pedagógica. No caso da literatura portuguesa, encontramos dois nomes importantes, Sampaio Bruno (da geração precedente) e Fernando Pessoa 
(contemporâneo de José de Macedo) que recorrem a estéticas semelhantes à utilizada por este autor.

J. Bravo Carbonel fala da sua experiência, mas de modo indireto, chegando a aparecer nas citações como se fosse uma terceira pessoa, afastando-o de certo modo do leitor, o que também é resultante do facto de uma parte considerável do livro incidir, sobretudo, na descrição que envolve já o modo como o autor vê a realidade. Numa descrição sobre um "selvaje atentado de los buvis del pueblo de Balachá", o autor introduz uma descrição em que o próprio é referido “(... ) se pusieron en camino las fuerzas de aquel puesto, á las que se unió voluntariamente el redactor jefe de esta revista" (BRAVO CARBONEL, p. 197-203). O leitor permanece passivo, sobretudo, porque a natureza exótica e as populações "bárbaras" são para si desconhecidas. A distância face à realidade europeia constantemente invade o discurso e o seu público, radicado na Europa, que é apenas leitor e não experimentador da realidade africana. Este precisa de senti-la assim mesmo pela palavra escrita em texto, daí a prodigalidade de descrições apelando à construção imaginária do leitor.

Assim sendo, ambos os autores recorrem à sua vivência como âncora dos seus textos. A sua experiência mais ou menos real, mais ou menos emocionante, mais ou menos sentida, insere o autor/narrador na realidade contada, se bem que como personagens extrínsecas como o são todos os colonos temporários destas terras, logo desta realidade tropical e colonial, apesar de José de Macedo retratar o seu envolvimento profundo com a comunidade local. Sai reforçada a verosimilitude do discurso que o leitor acredita transportá-lo verdadeiramente para a Guiné Equatorial ou para Angola, por basear-se na experiência real. Forja-se o conhecimento de algo distante e, afinal, perfeitamente desconhecido da massa de leitores e até de pensadores destas duas metrópoles.

Os dois autores exortam à mudança, daí o apelo ao leitor e o repetido argumento da experiência. J. Bravo Carbonel elege como objetivo o reforço dos laços coloniais entre Espanha e a Guiné 
Equatorial, José de Macedo tem por finalidade a progressiva descentralização que deveria desembocar numa verdadeira autonomia. Ambos pensam assim atingir o progresso de que tão necessitadas estão aquelas paragens. Porém, as ideias de desenvolvimento que defendem são muito diferentes, um coloca o ponto nevrálgico no trabalho indígena e o outro na educação de toda a população que compõe a colónia. São ideias de progresso, de colonização e de participação do colonizado, afinal, divergentes, apesar de fundamentadas num mesmo aspeto: a melhoria das condições de vida daquelas terras e populações. São esses conceitos que fundamentam o seu discurso que os levam a optar por soluções estéticas e discursivas bem diversas.

\section{Em torno de mistério, riqueza, colonização e autonomia}

Como começámos por dizer a forma do discurso, o seu conteúdo e objetivo têm uma relação indissociável, servindo em ambos os casos para a receção não só passiva como ativa da obra por parte do leitor que deverá aderir às propostas ali expostas e para estas contribuir. Deste modo, tanto em termos de linguagem como de recursos estilísticos, as obras cumprem percursos diferentes, já que, embora se dirijam aos públicos metropolitanos que têm curiosidade ou algum interesse nas questões coloniais e apenas subsidiariamente a um público diretamente relacionado com as colónias, sobretudo, no caso de J. Bravo Carbonel, já que José Macedo ao escrever este livro cumpre um desejo antigo, partilhado com os antigos companheiros e amigos de Angola (o que lá poderia despertar algum interesse pelo livro), os seus objetivos são diversos. J. Bravo Carbonel escreve para impulsionar a colonização branca, o trabalho autóctone e uma presença efetiva da administração colonial nos territórios. José de Macedo escreve para promover uma maior autonomia da colónia face ao governo central metropolitano e a educação de colono e colonizado em território colonial.

J. Bravo Carbonel reforça o caráter exótico dos conteúdos que descreve através do recurso a figuras de estilo que concedem forma 
airosa e atraente ao texto, por meio de metáforas, enumerações, adjetivações, oposições, que causam no leitor o acompanhamento interessado e o seu transporte para a realidade lida. Os aspetos selvático e insubmisso da natureza, expectante que alguém a vá dominar, são apresentados, assim como é referida como solução a ida em massa do colono espanhol a quem caberia dominar e aproveitar toda essa pujança espontânea. Igualmente as populações são apresentadas como distantes de nós, imorais, quase primárias como os animais, portanto, necessitadas de submissão. A paisagem ecológica do território, incluindo a existência humana, surge assente em substantivação e adjetivação fortemente sexualizada (repetindo-se palavras como luxúria, para descrever o crepúsculo, por exemplo, virgindade, reprodução, fertilidade, prazer, desejo, atraente) e mistificada, com recurso à criação da imagem do desconhecido por conquistar (através de palavras como mistério, escuridão, noite, desbravar, submeter).

Os argumentos do autor, seja a propósito de que tema for, são entrecortados por descrições apelativas à imaginação e que satisfazem a curiosidade e as ideias preconcebidas a partir daí construídas. Como consequência, tudo se resume a um tópico: a existência de uma realidade que aguarda por ser dominada e enriquecida através da colonização. O estímulo da visão exótica do espaço liga-se diretamente ao seu objetivo de mostrar o quanto é necessária a intervenção do leitor e de toda uma nação com deveres “civilizatórios”, porque o autóctone não vai conseguir extrair nada daquele território, tal como nunca conseguiu. Assim, surgem algumas descrições com ambições etnográficas e do meio ambiente, pejadas de artificios que as transformam em algo distante, mas que está ao alcance do leitor, em sentido real (através da ida para lá como colono) e em sentido figurativo (transportando-se através do texto).

Em José de Macedo encontramos um discurso bem distante deste. O seu texto está prenhe de informações, prestadas em tom coloquial, num permanente diálogo com o leitor (MACEDO, p. 56-57). 
Para reforçar a objetividade que pretende dar ao texto, retira-lhe todos os artificios estilísticos a que recorre o autor precedente. Compensa esta aparente aridez do discurso com uma pontuação forte, repleta de exclamações e de interjeições ao leitor, contrabalançando na pontuação a ausência de outros recursos literários que embelezam o texto. O discurso constitui-se como um todo, sem repetições e sempre com um raciocínio que tem uma linha condutora: provar que a descentralização progressiva, tendente à autonomia, é a única forma de resolver os problemas de Angola e de prepará-la para uma futura independência, quando tivesse condições para tal. Deste modo, o caráter objetivo do texto e a precisão do discurso eram um requisito para o autor que pretende levar o leitor a pensar consigo o tema e as soluções para uma nova administração colonial em Angola que assegurasse o progresso da colónia. Com elites locais minimamente preparadas para iniciar o processo, José de Macedo não vê aquele território como estando repleto de exotismo ou divergente face à metrópole, antes parece-lhe a administração colonial ser apenas um prolongamento de alguns erros cometidos também na capital, isto é, no âmbito da administração central em geral.

\section{Conclusão}

J. Bravo Carbonel e José de Macedo preconizaram duas leituras dos trópicos bem diferentes. Divergências estas que se prolongam nas formas textuais que escolheram para defender os seus objetivos, um encaminhando-nos para um discurso pejado de exotismo, o outro guiando-nos num texto racional e pretensamente objetivo, contudo repleto de emotividade.

Estes dois casos exemplificam o facto mais lato de a literatura colonial produzida nos vários países ser variada e divergente nos discursos produzidos, tanto nos aparentes relatos do real como nas propostas alternativas à realidade, tanto encontramos textos belos e 
ficcionais como textos mais objetivos e pegados à realidade experimentada. Só lendo os vários autores, comparando as suas obras, procurando os seus trilhos e analisando os textos nas suas formas e conteúdos, poderemos ter uma ideia do que constituiu a visão colonial do mundo, seja esta real ou utópica. Neste caso, Bravo Carbonel aproximou-se mais do que constituiu o sistema colonial vigente e que vigorou aproximadamente da mesma forma durante mais cinco décadas. José de Macedo construiu uma utopia que não deixou de conter em si a realidade, quando fez a projeção: escolham: autonomia ou liberdade (MACEDO, p. 242), pois cinquenta anos após a edição do livro, levantaram-se as armas e iniciou-se uma longa guerra colonial pela independência.

\section{Referências bibliográficas}

AAVV. Teorías de la ficción literaria. Madrid: Arco/libros, S. L., 1997. BRUNO, Sampaio. Os modernos publicistas portugueses. Porto: Livraria Chardron/Lello \& Irmão Editores, 1987.

CARBONEL, J. Bravo. Fernando Poo y el Muni: sus misterios y riquezas. Su colonización. Madrid: Imprenta de “Alrededor del Mundo”, 1917. ECO, Umberto. O signo. 6.ed. Lisboa: Presença, 2004.

JAUSS, Hans Robert. A literatura como provocação (história da literatura como provocação literária), 2.ed. Vega: Lisboa, 2003.

LOTMAN, Iuri. "Um modelo dinâmico do sistema semiótico." In: Ensaios de semiótica soviética. Lisboa: Horizonte, 1981, p. 67-86.

LOTMAN, Iuri, USPENSKI, Boris A. "Sobre o mecanismo semiótico da cultura." In: Ensaios de semiótica soviética. Lisboa: Horizonte, 1981, p. 37-65.

MACEDO, José. Autonomia de Angola. 3.ed. Lisboa: Instituto de Investigação Científica Tropical, 2008.

MACEDO, José. Autonomia de Angola: estudo de administração colonial. Lisboa: Editor o Autor, Typographia Leiria, 1910. 
MARCELINO, Antonio Joaquim [editor]. A Defeza de Angola : libertando pela paz, egualando pela justiça, progredindo pela autonomia, Luanda, [1903]-1907.

PESSOA, Fernando. A nova poesia portuguesa sociologicamente considerada. Lisboa: Nova Ática, 2006.

PESSOA, Fernando. O interregno: defesa e justificação da ditadura militar em Portugal. Lisboa: Nova Ática, 2007.

SAID, Edward. Orientalismo. 2.ed. Lisboa: Cotovia, 2004.

SOARES, Francisco. Notícia da literatura angolana. Lisboa: Imprensa Nacional- Casa da Moeda, 2001.

SOARES,Francisco.Teoria da literatura, criatividade $e$ estrutura.Luanda:Kilombelombe, 2007. 